\title{
3 Research Square

\section{Heritability and Multipoint Linkage Analysis Suggest the Contribution of Angiopoietin-TEK Pathway to the Variation of Serum Creatinine and Glomerular Filtration Rate}

Fahad Zadjali ( $\square$ fahadz@squ.edu.om )

Sultan Qaboos University

Mazin Al-Wahaibi

Oman Medical Specialty Board

Mohammed O. Hassan

Canadian Health Centre

Riad A. Bayoumi

Mohammed Bin Rashid University for Medicine and Health Science

Razan Zadjali

Sultan Qaboos University

Sulayma Albarwani

Sultan Qaboos University

Nafila B Al Riyami

Sultan Qaboos University

Saeed Al-Yahyaee

Sultan Qaboos University

Research Article

Keywords: genetic variability, kidney function, pedigrees, gene mapping

Posted Date: February 14th, 2022

DOI: https://doi.org/10.21203/rs.3.rs-1242689/v1

License: (c) (i) This work is licensed under a Creative Commons Attribution 4.0 International License.

Read Full License 


\section{Abstract}

Background: Serum creatinine and estimated glomerular filtration rate (eGFR) are keys to assess kidney function and suggest a propensity for development of renal failure. Genetic factors are reported in different ethnic groups to play a role in the variability of these phenotypes. In this study, we investigate the heritability and quantitative trait loci (QTL) of serum creatinine and eGFR. Multiple phenotypes were collected from a multi-generation pedigree of 281 subjects form Oman family study. Genotype analysis was used to calculate heritability and linkage was performed using variance components decompositionbased methods implemented in SOLAR.

Results: The multivariate-adjusted heritability estimates for serum creatinine and eGFR were 0.70 and 0.63 (p-value $2.5 \times 10-11$ and 1.8x10-11), respectively. Genome-wide linkage analysis showed significant loci with LOD score $\geq 2$ at chromosomes 9p21.1, 9p21.3, 15p26.3 and 16.p13.3. Functional annotation identified angiopoietin 1-TEK pathway as a candidate pathway where TEK is associated with chronic kidney disease and expressed in renal glomeruli.

Conclusion: This study showed high heritability of serum creatinine and eGFR with significant QTLs in chromosomes 9,15 and 16. Further research is needed to study the genetic association studies of angiopoietin 1-TEK axis with glomerulopathies like type 2 diabetes and to predict and diagnose progression of renal diseases.

\section{Introduction}

End-stage renal diseases (ESRDs) are strongcontributors to morbidity and mortality worldwide(Mortality \& Causes of Death, 2016).Patients with ESRD are more susceptible to associated complications including being at higher risk of cardiovascular disease development (Baigent, Burbury, \& Wheeler, 2000). Serum creatinine and estimated glomerular filtration rate (eGFR) arefrequently used to measure kidney functionto serve in diagnosis, to monitor disease progression, and evaluate therapeutic responses. Serum creatinine, produced by creatine phosphate metabolism, reflectseGFR to a reasonable extent and confounded by factors such as muscle mass, age, race, and gender (Stevens et al., 2008).

The intricacy of genetic and environmental factors has been previously investigated in relation to serum creatinine and eGFR(Fox et al., 2004; Langefeld et al., 2004; Thameem et al., 2013). Genome-wide linkage analyses (GWAS) of kidney function conducted in a range of populations identified genomic loci variants associated with kidney traits, including serum creatinine and eGFR variations(Fox et al., 2004; Hwang, Yang, Meigs, Pearce, \& Fox, 2007; Kottgen, 2010; Liu et al., 2011; Moulin et al., 2017).Evidence across various ethnic groups identifiedpositional candidate genes that influence measures of renal function, their functional significance remains to be investigated. Establishing the heritability of renal function parametersin different ethnic groups would reinforce the phenotypic variabilityand could suggest genetic factors in estimation of renal filtration capacity. This study aimed to measure the heritability $\left(h^{2} R\right)$ and 
identify quantitative trait locus (QTL) of serum creatinine and eGFR in an Arab ethnic population using family-based measured genotype analysis.

\section{Results}

\section{Characteristics of participants and pedigree analyses}

The structure of the pedigree and the relationship between members were shown in Table 1. The pedigree consisted of 23 sub-pedigrees with intermarriages and a total of 148 nuclear families with 109 founder individuals. The pedigree was highly extended with maximum relation reached to the 9-degree kinship. The mean age was 31 years, $53 \%(n=149)$ were females and $47 \%(n=132)$ were males.Gender differences were observed in serum creatinine (male $73.33 \pm 17.29$ vs female $47.68 \pm 10.32$ ) and eGFR (male 120.54 \pm 36.67 vs female $142.34 \pm 38.81$, $p$-value $<0.001$, Table 2 .

\section{Parameters that correlate with serum creatinine and eGFR}

In the polygenic model covariates are used to strengthen the estimation of heritability and quantitative trait loci. To identify covariate, we run correlation matrix of all phenotypes against serum creatinine and eGFR, Figure 1. Serum creatinine had strong correlation with eGFR ( $r$-coefficient -0.77 , p-value $<0.0001$ ), Figure 1. It had weaker correlation with age, serum triglyceride, BMI and waist circumference. eGFR had moderate correlation with age ( $r$-correlation coefficient -0.48 , $p$-value $<0.0001)$ and weak correlation with total cholesterol, triglyceride, body mass index (BMI) and waist circumference. Fasting blood sugarwas not significantly correlation with serum creatinine and eGFR, Figure 1.From the correlation analysis, we selected total cholesterol, serum triglycerides, BMI,waist circumference and age along with gender as covariates for further measured genotype analysis.

\section{Heritability of Serum Creatinine and eGFR}

We analysed the pedigree of 281 subjects to estimate the crude and adjusted heritabilityofserum creatinine and eGFR using variance component analysis in SOALR. Following covariates were used to adjust the heritability: age, gender, total serum cholesterol, serum triglycerides, $\mathrm{BMI}$, and waist circumference. Heritability $\left(\mathrm{H}^{2} \mathrm{R}\right)$ of serum creatinine was $0.64 \pm 0.19$ ( $\mathrm{p}$-value $\left.1.0 \times 10^{-7}\right)$ andwith covariate adjustment the $\mathrm{H}^{2} \mathrm{R}$ was increased $0.70 \pm 0.13$ ( $\mathrm{p}$-value $2.5 \times 10^{-11}$ ), Table 3 . While the $\mathrm{H}^{2} \mathrm{R}$ of eGFR was $0.37 \pm 0.12$ ( $p$-value $\left.2.1 \times 10^{-6}\right)$ and with adjustment $0.63 \pm 0.13\left(p\right.$-value $\left.1.8 \times 10^{-11}\right)$, Table 3 .

\section{Multipoint Quantitative Linkage Analyses of serum creatinine and eGFR}

We use measured genotype analysis in SOLAR to identify quantitative trait loci (QTL) that determine the heritability of serum creatinine and eGFR. We first analyzed the statistical power of the pedigree and the model to identify a significant QTL. Using the current genealogical information, Figure-2a shows that the pedigree had $80 \%$ power to detect a locus with a significant logarithm of the odds (LOD) score of $\geq 2$ with a trait heritability of $\sim 0.28$ and locus of LOD score of 3 with heritability of 0.24 . These values are lower 
than the measured heritability of serum creatinine and eGFR (Table 3), therefore the pedigree model has higher power to detect significant loci of LOD score of 2 and above.

To identify QTLs, each individual was genotyped at 343 microsatellite markers for a $10 \mathrm{cM}$ genome-wide scan.Since eGFR calculation involve serum creatinine, we observed overlapping multipoint genome-wide linkage peaks, Figure 2b-d. We found significant QTLs with LOD scores of $\geq 2$ with highest LOD score for serum creatinine was 2.43 on chromosome 16p13.3 at 25 cMbetween markersD16S2613 and D16S3047 (Table 4, Figure 2d) while for eGFR, a LOD score of 2.71 was detected at chromosome $15 \mathrm{p} 26.3$ at $138 \mathrm{cM}$ between the markers D15S87 and D15S642, Table 4 and Figure 2c. Two peaks were found at chromosome 9p21.1-p21.3 (44 and 51 cM) between D9S171 and D9S1853 markers, Table 4 and Figure $2 b$.

\section{Gene Mapping of significant quantitative trait loci:}

We performed bioinformatics search for genes located in the microsatellite region that showed significant LOD scores listed in Table 4. Total of 25 genes were identified in the chromosomal regions of significant linkage with serum creatinine and eGFR. Table 5 describes any reported genetic association with chronic kidney disease (GAD-CKD) and renal expression from two expression databases Unigene-EST and CGAPSAGE. TEK receptor tyrosine kinase (TEK) gene at chromosome 9 was found to have genetic association with chronic kidney disease and reported expression in normal and cancerous renal tissues.

\section{Discussion}

In this study, we examined the genetic contribution on serum creatinine and eGFR, known parameter of kidney function, and identified the quantitativeloci that contribute to the genetic variations of these parameters. With a family-based model adjusted for age, gender, total cholesterol, serum triglycerides, BMI and waist circumference as covariates, we found $63 \%$ and $70 \%$ of variations in eGFR and serum creatinine, respectively, are due to genetic component. We further identified four significant loci contributing to the heritability of kidney function parameters: 9p21.1, 9p21.3, 15p26.3 and 16.p13.3.

Our study reported high heritability values for serum creatinine and eGFR using a large multi-generation pedigree adjusted to multiple confounding variables. In type 2 diabetic patients, heritability of GFR was found high as $75 \%$ with adjustment of age, sex, mean arterial blood pressure, medications, and glycated hemoglobin(Langefeld et al., 2004). In the Framingham Heart Study, genome wide linkage analysis of 330 nuclear families found heritability of serum creatinine as $29 \%$ and $33 \%$ for eGFR adjusted for age, gender, BMI, diabetes, systolic BP, hypertension treatment, tobacco use, and HDL cholesterol(Fox et al., 2004). In the Swedish Twins-based study, the heritability of serum creatinine was reported as $19 \%$, creatinine based-eGFR as $18.6 \%$ and Cystatin-C-based eGFR as $41.8 \%$ (Arpegard et al., 2015). Another United Kingdom twin study reported heritability of creatinine of $37 \%$ and eGFR as $63 \%$ (Hunter et al., 2002). The differences in reported heritability of serum creatinine and eGFR is attributed to the ethnicity of participants under the study or inclusion of patient population. Altogether, these studies suggest strong genetic component in the variability of serum creatinine and eGFR. This provide insights to find the genes 
that are associated with these biochemical measures and improve the understanding in the variation of kidney function within a population.

we used a validated genetic model of extended pedigree structure with heritability estimation extended up to $9^{\text {th }}$ degree kinship. We identify QTLs for serum creatinine and eGFR in three chromosomes 9,15 and 16. Prior genome-wide linkage studies identified various QTLs influencing serum creatinine-based eGFR, but none reported significant LOD scores on chromosomes 9, 15, and 16 (Hunt et al., 2004). In Strong Heart Family study, linkage analysis identified significant association between eGFR and SNPs within SLC6A13 (ch.12p13.33),UBE2Q2 (ch.15q24.2), PIP5K1B (ch19p12), and WDR72

(ch15q21.3)genes(Franceschini et al., 2014). One of the candidate gene in contributing to genetic variability in kidney function is Tyrosine kinase receptor (TEK) that ismainly expressed on endothelial cells and serves as a receptor for angiopoietin-1 (ANGPT1) (Suri et al., 1996). Glomerular capillaries are composed of a fenestrated endothelium and specialised epithelial cells (the podocytes).ANGPT1-induced TEK signalling pathway regulates cell survival, quiescence, proliferation, migration, adhesion, and vascular permeability (Suri et al., 1996). Therefore, the role of angiopoietins is important in glomerular function in healthy and disease state(Gnudi, 2016). ANGPT1is constitutively expressed in podocytes(Satchell et al., 2002) while TEK expression is localised in the endothelium of mouse glomerular capillaries (Yuan, Suri, Yancopoulos, \& Woolf, 1999) and podocyte of rat kidneys(DessaptBaradez et al., 2014).. Moreover, heterozygous deletion of TEK in mice results in reducedglomerular vasculature(Puri, Partanen, Rossant, \& Bernstein, 1999). In human, defects in TEK causes an autosomal dominant form of venous malformation (Fukuhara et al., 2008; Wouters et al., 2010) which manifests with abnormalities in kidney function (Cura, Elmerhi, Suri, Bugnone, \& Dalsaso, 2010).

\section{Conclusion}

Our study reported high genetic component of serum creatinine and eGFR with significant contribution of loci in chromosomes 9,15 and 16 to the heritability of these parameters. We suggest future genetic association studies of ANGPT1-TEK axis with diseases associated with glomerulopathies like type 2 diabetes (Dessapt-Baradez et al., 2014).

\section{Methods}

\section{Study Population: Oman Family Study}

Data of the study participants was all obtained from Oman Family study, a family-based genetic model (Bayoumi et al., 2007; Zadjali, Al-Yahyaee, Hassan, Albarwani, \& Bayoumi, 2013). The data included family medical history, demographic data, and lifestyle. Out of five highly consanguineous families, one family consisting of 281 individuals was selected because of availability of serum creatinine and eGFR measurements. All methods were carried out in accordance with relevant guidelines and regulations. The study was approved by the ethics committee in Sultan Qaboos University and written informed consent was obtained from each participant. 


\section{Measurement of phenotypic data}

Multiple phenotypic data were collected in Oman family study, described earlier (Hassan et al., 2011; Zadjali et al., 2013). Body weight and height were used to calculate body mass index (BMI), and waist circumference was measured. Blood samples were obtained from overnight fasted subjects in nonadditive tubes (Becton Dickinson and Company, USA) and serum was obtained after centrifugation. Serum creatinine were measured along other biochemical parameters using Rocha Cobas Integra- 400 (Roche Diagnostics, Germany). Total cholesterol, total serum triglycerides, blood glucose, and lipoproteins levels were assayed by enzymatic calorimetric methods. Serum creatinine was corrected using the Jaffe method using following formula corrected-creatinine $=1.058 \times$ (serum creatinine) -15.951 . GFR was estimated using the Modification of Diet in Renal Disease equation (MDRD)(Levey et al., 1999): eGFR $(\mathrm{mL} / \mathrm{min} / 1.73 \mathrm{~m} 2)=175 \times(\text { Corrected serum creatinine } \mu \mathrm{mol} / \mathrm{L} \times 0.0113)^{-1.154} \times(\text { Age })^{-0.203} \times(0.742$ if female)

\section{Descriptive statistics:}

Baseline characteristics were analyzed using IBM SPSS statistics v.21. and expressed as mean \pm standard deviation. To test the normal distribution, Kolmogorov-Smirnov test was carried out. MannWhitney $U$ test was performed for non-normal distributed data. A two tailed $\mathrm{P}<0.05$ was considered significant. Pearson correlation and scatter plot matrix were generated using R statistical software (Foundation for Statistical Computing, Vienna, Austria).

\section{Heritability and genome-wide quantitative linkage analysis:}

Heritability is defined as the ratio of genetic variability in traits attributable to individual alleles(Zuk, Hechter, Sunyaev, \& Lander, 2012). To estimate crude $h^{2} R$ for serum creatinine and eGFR, we used the Sequential Oligogenic Linkage Analysis Routines (SOLAR) software package (Almasy \& Blangero, 1998; Amos, 1994). The expected effect of all measured covariates on eGFR was further computed. To achieve normality, data that showed kurtosis by redefining the traits using normalization function using SOLAR.

To perform multipoint linkage analysis, we first determined the pedigree power to determine a significant locus of LOD score of 2 and 3 at different trait heritability values. Power calculation was performed using the Sequential Oligogenic Linkage Analysis Routines (SOLAR) software package (Version 4.1.7)(Almasy \& Blangero, 1998). Subsequently, we collected the genotype data for each subject analyzed previously (Hassan et al., 2011). Briefly, genotype results were collected for 343 microsatellite markers for a $10 \mathrm{cM}$ genome-wide scan by the Mammalian Genotyping Services at Marshfield Clinic Research Foundation (http://research.marshfield- clinic.org/genetics). Identity by descent was calculated using all information provided in the pedigree to scan for allele sharing probabilities between the individuals. Genotype information was used to determine quantitative trait loci (QTL); loci associated with phenotypic variance and characterized by related individuals sharing 0,1 , or 2 alleles (Fox et al., 2004). Logarithm of odds (LOD) scores were calculated and adjusted with the covariates for each trait in order to perform 
multipoint quantitative linkage analysis (SOLAR). LOD scores ${ }^{3} 2$ were considered significant (Almasy \& Blangero, 1998).

\section{Functional annotations of Genes under QTL regions:}

We collected the list of genes within the significant QTL regions that determines serum creatinine and eGFR heritability. We searched for gene-disease mappings Genetic Association Database for any kidney disease (GAD-CKD) (Becker, Barnes, Bright, \& Wang, 2004) and also search for tissue expression using two databases: Unigene-EST and Cancer Genome Anatomy Project (CGAP)-serial analysis of gene expression (CGAP-SAGE) (Boon et al., 2002).

\section{Abbreviations}

ANGPT1: angiopoietin-1; BMI: Body Mass Index; cM: centimorgan;eGFR: estimated glomerular filtration rate; ESRDs: End-stage renal diseases; GAD-CKD : genetic association with chronic kidney disease; $\mathrm{H}^{2} \mathrm{R}$ : heritability; LOD: logarithm of the odds; QTL: quantitative trait loci; TEK: TEK receptor tyrosine kinase

\section{Declarations}

\section{Ethics approval and consent to participate:}

All methods were carried out in accordance with relevant guidelines and regulations. The study was approved by the ethics committee in Sultan Qaboos University and written informed consent was obtained from each participant.

\section{Consent for publication}

Not Applicable.

\section{Availability of data and materials}

The raw datasets (pedigree files and microsatellite genotypes) used and analyzed during the current study are not depositedin publicly available repositories because of considerations about the security ofhuman genetic resources but the data is available upon request to the corresponding author.No sequence or array files are generated form the study to be deposited in relevant databases.

\section{Competing interests}

The authors have declared no competing interests.

\section{Funding}

This work was supported by His Majesty Trust Fund (Grant SR/MED/PHYS/04/ 01). 


\section{Authors' contributions}

FZ, M.O.H, R.A.B, S.Alb, S.A designed the study. F.Z designed the method of analysis.F.Z and M.A performed the analyses. FZ, M.O.H, R.A.B, S.Alb, S.A, N.B.A and RZ assisted with interpretation. F.Z wrote the manuscript. All authors reviewed the manuscript. The authors read and approved the final manuscript.

\section{Acknowledgements}

We would like to thank the team of Oman Family study to provide the data for this study and also thank Dr V. Saroja Voruganti to provide the processed multipoint data.

\section{Consent for Participation}

Not applicable

\section{References}

1. Almasy, L., \& Blangero, J. (1998). Multipoint quantitative-trait linkage analysis in general pedigrees. Am J Hum Genet, 62(5), 1198-1211. doi:10.1086/301844

2. Amos, C. I. (1994). Robust variance-components approach for assessing genetic linkage in pedigrees. Am J Hum Genet, 54(3), 535-543. Retrieved from https://www.ncbi.nlm.nih.gov/pubmed/8116623

3. Arpegard, J., Viktorin, A., Chang, Z., de Faire, U., Magnusson, P. K., \& Svensson, P. (2015). Comparison of heritability of Cystatin $\mathrm{C}$ - and creatinine-based estimates of kidney function and their relation to heritability of cardiovascular disease. J Am Heart Assoc, 4(1), e001467. doi:10.1161/JAHA.114.001467

4. Baigent, C., Burbury, K., \& Wheeler, D. (2000). Premature cardiovascular disease in chronic renal failure. Lancet, 356(9224), 147-152. doi:10.1016/S0140-6736(00)02456-9

5. Bayoumi, R. A., Al-Yahyaee, S. A., Albarwani, S. A., Rizvi, S. G., Al-Hadabi, S., Al-Ubaidi, F. F., . . Hassan, M. O. (2007). Heritability of determinants of the metabolic syndrome among healthy Arabs of the Oman family study. Obesity (Silver Spring), 15(3), 551-556. doi:10.1038/oby.2007.555

6. Becker, K. G., Barnes, K. C., Bright, T. J., \& Wang, S. A. (2004). The genetic association database. Nat Genet, 36(5), 431-432. doi:10.1038/ng0504-431

7. Boon, K., Osorio, E. C., Greenhut, S. F., Schaefer, C. F., Shoemaker, J., Polyak, K., . . Riggins, G. J. (2002). An anatomy of normal and malignant gene expression. Proc Natl Acad Sci U S A, 99(17), 11287-11292. doi:10.1073/pnas. 152324199

8. Cura, M., Elmerhi, F., Suri, R., Bugnone, A., \& Dalsaso, T. (2010). Vascular malformations and arteriovenous fistulas of the kidney. Acta Radiol, 51(2), 144-149. doi:10.3109/02841850903463646 
9. Dessapt-Baradez, C., Woolf, A. S., White, K. E., Pan, J., Huang, J. L., Hayward, A. A., . . Gnudi, L. (2014). Targeted glomerular angiopoietin-1 therapy for early diabetic kidney disease. J Am Soc Nephrol, 25(1), 33-42. doi:10.1681/ASN.2012121218

10. Fox, C. S., Yang, Q., Cupples, L. A., Guo, C. Y., Larson, M. G., Leip, E. P., .. Levy, D. (2004). Genomewide linkage analysis to serum creatinine, GFR, and creatinine clearance in a communitybased population: the Framingham Heart Study. J Am Soc Nephrol, 15(9), 2457-2461. doi:10.1097/01.ASN.0000135972.13396.6F

11. Franceschini, N., Haack, K., Almasy, L., Laston, S., Lee, E. T., Best, L. G., . . Cole, S. A. (2014). Generalization of associations of kidney-related genetic loci to American Indians. Clin J Am SoC Nephrol, 9(1), 150-158. doi:10.2215/CJN.02300213

12. Fukuhara, S., Sako, K., Minami, T., Noda, K., Kim, H. Z., Kodama, T., . . Mochizuki, N. (2008). Differential function of Tie2 at cell-cell contacts and cell-substratum contacts regulated by angiopoietin-1. Nat Cell Biol, 10(5), 513-526. doi:10.1038/ncb1714

13. Gnudi, L. (2016). Angiopoietins and diabetic nephropathy. Diabetologia, 59(8), 1616-1620. doi:10.1007/s00125-016-3995-3

14. Hassan, M. O., Jaju, D., Voruganti, V. S., Bayoumi, R. A., Albarwani, S., Al-Yahyaee, S., . . Comuzzie, A. G. (2011). Genome-wide linkage analysis of hemodynamic parameters under mental and physical stress in extended Omani Arab pedigrees: the Oman Family Study. Twin Res Hum Genet, 14(3), 257267. doi:10.1375/twin.14.3.257

15. Hunt, S. C., Coon, H., Hasstedt, S. J., Cawthon, R. M., Camp, N. J., Wu, L. L., \& Hopkins, P. N. (2004). Linkage of serum creatinine and glomerular filtration rate to chromosome 2 in Utah pedigrees. Am J Hypertens, 17(6), 511-515. doi:10.1016/j.amjhyper.2004.02.019

16. Hunter, D. J., Lange, M., Snieder, H., MacGregor, A. J., Swaminathan, R., Thakker, R. V., \& Spector, T. D. (2002). Genetic contribution to renal function and electrolyte balance: a twin study. Clin Sci (Lond), 103(3), 259-265. doi:10.1042/cs1030259

17. Hwang, S. J., Yang, Q., Meigs, J. B., Pearce, E. N., \& Fox, C. S. (2007). A genome-wide association for kidney function and endocrine-related traits in the NHLBI's Framingham Heart Study. BMC Med Genet, 8 Suppl 1, S10. doi:10.1186/1471-2350-8-S1-S10

18. Kottgen, A. (2010). Genome-wide association studies in nephrology research. Am J Kidney Dis, 56(4), 743-758. doi:10.1053/j.ajkd.2010.05.018

19. Langefeld, C. D., Beck, S. R., Bowden, D. W., Rich, S. S., Wagenknecht, L. E., \& Freedman, B. I. (2004). Heritability of GFR and albuminuria in Caucasians with type 2 diabetes mellitus. Am J Kidney Dis, 43(5), 796-800. doi:10.1053/j.ajkd.2003.12.043

20. Levey, A. S., Bosch, J. P., Lewis, J. B., Greene, T., Rogers, N., \& Roth, D. (1999). A more accurate method to estimate glomerular filtration rate from serum creatinine: a new prediction equation. Modification of Diet in Renal Disease Study Group. Ann Intern Med, 130(6), 461-470. doi:10.7326/0003-4819-130-6-199903160-00002 
21. Liu, C. T., Garnaas, M. K., Tin, A., Kottgen, A., Franceschini, N., Peralta, C. A., ... Fox, C. S. (2011). Genetic association for renal traits among participants of African ancestry reveals new loci for renal function. PLoS Genet, 7(9), e1002264. doi:10.1371/journal.pgen.1002264

22. Mortality, G. B. D., \& Causes of Death, C. (2016). Global, regional, and national life expectancy, allcause mortality, and cause-specific mortality for 249 causes of death, 1980-2015: a systematic analysis for the Global Burden of Disease Study 2015. Lancet, 388(10053), 1459-1544. doi:10.1016/S0140-6736(16)31012-1

23. Moulin, F., Ponte, B., Pruijm, M., Ackermann, D., Bouatou, Y., Guessous, I., . . Bochud, M. (2017). A population-based approach to assess the heritability and distribution of renal handling of electrolytes. Kidney Int, 92(6), 1536-1543. doi:10.1016/j.kint.2017.06.020

24. Puri, M. C., Partanen, J., Rossant, J., \& Bernstein, A. (1999). Interaction of the TEK and TIE receptor tyrosine kinases during cardiovascular development. Development, 126(20), 4569-4580. Retrieved from https://www.ncbi.nlm.nih.gov/pubmed/10498691

25. Satchell, S. C., Harper, S. J., Tooke, J. E., Kerjaschki, D., Saleem, M. A., \& Mathieson, P. W. (2002). Human podocytes express angiopoietin 1, a potential regulator of glomerular vascular endothelial growth factor. J Am Soc Nephrol, 13(2), 544-550. Retrieved from https://www.ncbi.nlm.nih.gov/pubmed/11805186

26. Stevens, L. A., Coresh, J., Schmid, C. H., Feldman, H. I., Froissart, M., Kusek, J., . . Levey, A. S. (2008). Estimating GFR using serum cystatin $\mathrm{C}$ alone and in combination with serum creatinine: a pooled analysis of 3,418 individuals with CKD. Am J Kidney Dis, 51(3), 395-406. doi:10.1053/j.ajkd.2007.11.018

27. Suri, C., Jones, P. F., Patan, S., Bartunkova, S., Maisonpierre, P. C., Davis, S., . . Yancopoulos, G. D. (1996). Requisite role of angiopoietin-1, a ligand for the TIE2 receptor, during embryonic angiogenesis. Cell, 87(7), 1171-1180. doi:10.1016/s0092-8674(00)81813-9

28. Thameem, F., Igo, R. P., Jr., Freedman, B. I., Langefeld, C., Hanson, R. L., Schelling, J. R., . . Diabetes Research, G. (2013). A genome-wide search for linkage of estimated glomerular filtration rate (eGFR) in the Family Investigation of Nephropathy and Diabetes (FIND). PLoS One, 8(12), e81888. doi:10.1371/journal.pone.0081888

29. Wouters, V., Limaye, N., Uebelhoer, M., Irrthum, A., Boon, L. M., Mulliken, J. B., . . Vikkula, M. (2010). Hereditary cutaneomucosal venous malformations are caused by TIE2 mutations with widely variable hyper-phosphorylating effects. Eur J Hum Genet, 18(4), 414-420. doi:10.1038/ejhg.2009.193

30. Yuan, H. T., Suri, C., Yancopoulos, G. D., \& Woolf, A. S. (1999). Expression of angiopoietin-1, angiopoietin-2, and the Tie-2 receptor tyrosine kinase during mouse kidney maturation. J Am Soc Nephrol, 10(8), 1722-1736. Retrieved from https://www.ncbi.nlm.nih.gov/pubmed/10446940

31. Zadjali, F., Al-Yahyaee, S., Hassan, M. O., Albarwani, S., \& Bayoumi, R. A. (2013). Association of adiponectin promoter variants with traits and clusters of metabolic syndrome in Arabs: family-based study. Gene, 527(2), 663-669. doi:10.1016/j.gene.2013.06.057 
32. Zuk, O., Hechter, E., Sunyaev, S. R., \& Lander, E. S. (2012). The mystery of missing heritability: Genetic interactions create phantom heritability. Proc Natl Acad Sci U S A, 109(4), 1193-1198. doi:10.1073/pnas.1119675109

\section{Tables}

Table 1: descriptive analysis of pedigree structure

\begin{tabular}{|ll|}
\hline & Number \\
\hline Sub-pedigree & 23 \\
\hline Nuclear families & 148 \\
\hline Founders & 109 \\
\hline Number of pedigree relation pairs & 651 \\
\hline Parent- offspring & \\
\hline Siblings & 438 \\
\hline grandparent- grandchild & 980 \\
\hline Avuncular & 1030 \\
\hline Half sibling & 159 \\
\hline 3rd degree & 5252 \\
\hline 4th degree & 7210 \\
\hline 5th degree & 6794 \\
\hline 6th degree & 2592 \\
\hline 7th degree & 755 \\
\hline 8th degree & 301 \\
\hline 9th degree & 59 \\
\hline
\end{tabular}

Table 2: Descriptive characteristics of pedigree members 


\begin{tabular}{|lllll|}
\hline & Total & Male & Female & p-value \\
\hline Number & 281 & $149(53.0 \%)$ & $132(47.0 \%)$ & \\
\hline Age (years) & $31(15)$ & $28(13)$ & $33(17)$ & n.s \\
\hline Fasting blood glucose $(\mathrm{mmol} / \mathrm{L})$ & $5.48(1.37)$ & $5.31(0.59)$ & $5.64(1.78)$ & n.s \\
\hline Total Cholesterol $(\mathrm{mmol} / \mathrm{L})$ & $4.54(1.04)$ & $4.36(0.94)$ & $4.71(1.10)$ & $<0.01$ \\
\hline Serum Triglycerides $(\mathrm{mmol} / \mathrm{L})$ & $1.17(0.82)$ & $1.31(0.80)$ & $1.05(0.83)$ & $<0.001$ \\
\hline Serum creatinine $(\mu \mathrm{mol} / \mathrm{L})$ & $59.68(18.98)$ & $73.33(17.29)$ & $47.68(10.32)$ & $<0.001$ \\
\hline eGFR $\left(\mathrm{mL} / \mathrm{min} / 1.73 \mathrm{~m}^{2}\right)$ & $132.14(39.30)$ & $120.54(36.67)$ & $142.34(38.81)$ & $<0.001^{*}$ \\
\hline Body Mass Index $\left(\mathrm{Kg} / \mathrm{m}^{2}\right)$ & $24.70(6.43)$ & $24.99(7.42)$ & $24.43(5.39)$ & n.s \\
\hline Waist Circumference $(\mathrm{cm})$ & $78.41(15.09)$ & $80.28(14.90)$ & $76.74(15.11)$ & $<0.05^{*}$ \\
\hline
\end{tabular}

Data are shown with mean ( \pm standard deviations). Whitney $\mathrm{U}$ test was used as statistic test for skew distributed phenotypes. *normally distributed phenotypes analysed byStudent $t$ test. n.s : statistically not significant.

Table 3. Heritability of serum creatinine and eGFR

\begin{tabular}{|lllll|}
\hline \multicolumn{4}{ll}{ Serum Creatinine } & eGFR \\
& $\mathrm{H}^{2} \mathrm{R}(\mathrm{SE})$ & $\mathrm{p}$-value & $\mathrm{H}^{2} \mathrm{R}(\mathrm{SE})$ & $\mathrm{p}$-value \\
\hline Crude & $0.64(0.19)$ & $1.0 \times 10^{-7}$ & $0.37(0.12)$ & $2.1 \times 10^{-6}$ \\
\hline adjusted & $0.70(0.13)$ & $2.5 \times 10^{-11}$ & $0.63(0.12)$ & $1.8 \times 10^{-11}$ \\
\hline
\end{tabular}

Heritability was adjusted using following covariates: age, gender, total serum cholesterol, serum triglycerides, BMI, and waist circumference

Table 4: Genome-wide scan for serum creatinine and eGFR

\begin{tabular}{|lllll|}
\hline Chr. & peak cM & markers & serum Creatinine & eGFR \\
\cline { 4 - 5 } & & & LOD & LOD \\
\hline $9 p 21.1$ & 44 & D9S171-D9S1853 & 2.33 & 2 \\
\hline $9 p 21.3$ & 51 & D9S171-D9S1853 & 2.28 & - \\
\hline $15 p 26.3$ & 138 & D15S87-D15S642 & 2.29 & 2.71 \\
\hline $16 p 13.3$ & 25 & D16S2613-D16S3047 & 2.43 & 2.25 \\
\hline
\end{tabular}


LOD: $\log$ of the odds ratio. LOD score of $\geq 2$ considered significant. cM: centimorgan position in each chromosome.

Table 5: Genes identified in linked regions of chromosomes 9, 15 and 16. 


\begin{tabular}{|c|c|c|c|c|c|}
\hline Gene & Name & Chr. & $\begin{array}{l}\text { GAD- } \\
\text { CKD }\end{array}$ & $\begin{array}{l}\text { Unigene } \\
\text { EST }\end{array}$ & $\begin{array}{l}\text { CGAP- } \\
\text { SAGE }\end{array}$ \\
\hline MOB3B & MOB kinase activator $3 \mathrm{~B}$ & 9 & & + & + \\
\hline $\begin{array}{l}\text { IFT74- } \\
\text { AS1 }\end{array}$ & IFT74 antisense RNA 1 & 9 & & & \\
\hline EQTN & equatorin & 9 & & & \\
\hline IFNK & interferon kappa & 9 & & + & \\
\hline IFT74 & intraflagellar transport 74 & 9 & & & \\
\hline PLAA & phospholipase $\mathrm{A} 2$ activating protein & 9 & & & + \\
\hline TEK & TEK receptor tyrosine kinase & 9 & + & + & + \\
\hline IZUMO3 & IZUMO family member 3 & 9 & & & \\
\hline CAAP1 & $\begin{array}{l}\text { caspase activity and apoptosis inhibitor } \\
1\end{array}$ & 9 & & & \\
\hline MIR876 & microRNA 876 & 9 & & & \\
\hline TUSC1 & tumor suppressor candidate 1 & 9 & & & \\
\hline LINGO2 & $\begin{array}{l}\text { leucine rich repeat and Ig domain } \\
\text { containing } 2\end{array}$ & 9 & & & \\
\hline LRRC19 & leucine rich repeat containing 19 & 9 & & + & \\
\hline MIR873 & microRNA 873 & 9 & & & \\
\hline SNRPA1 & $\begin{array}{l}\text { small nuclear ribonucleoprotein } \\
\text { polypeptide A }\end{array}$ & 15 & & & + \\
\hline ASB7 & $\begin{array}{l}\text { ankyrin repeat and SOCS box containing } \\
7\end{array}$ & 15 & & + & \\
\hline ALDH1A3 & $\begin{array}{l}\text { aldehyde dehydrogenase } 1 \text { family } \\
\text { member } A 3\end{array}$ & 15 & & & \\
\hline LRRK1 & leucine rich repeat kinase 1 & 15 & & & \\
\hline TARSL2 & threonyl-tRNA synthetase like 2 & 15 & & & \\
\hline TM2D3 & TM2 domain containing 3 & 15 & & + & + \\
\hline CHSY1 & chondroitin sulfate synthase 1 & 15 & & & \\
\hline LINS & lines homolog 1 & 15 & & & \\
\hline RSL1D1 & ribosomal L1 domain containing 1 & 16 & & & + \\
\hline GSPT1 & G1 to $S$ phase transition 1 & 16 & & & \\
\hline PCSK6 & proprotein convertase subtilisin/kexin & 16 & & & + \\
\hline
\end{tabular}




\begin{tabular}{|lll|} 
& type 6 \\
SNN & stannin & 16 \\
\hline BCAR4 & breast cancer anti-estrogen resistance 4 & 16 \\
\hline LITAF & lipopolysaccharide induced TNF factor & 16 \\
\hline
\end{tabular}

Figures 


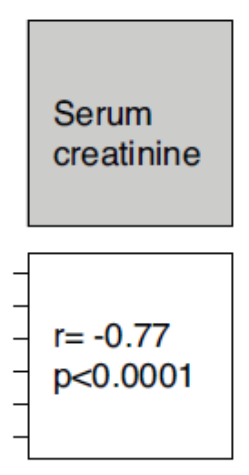

$50 \quad 150 \quad 250$
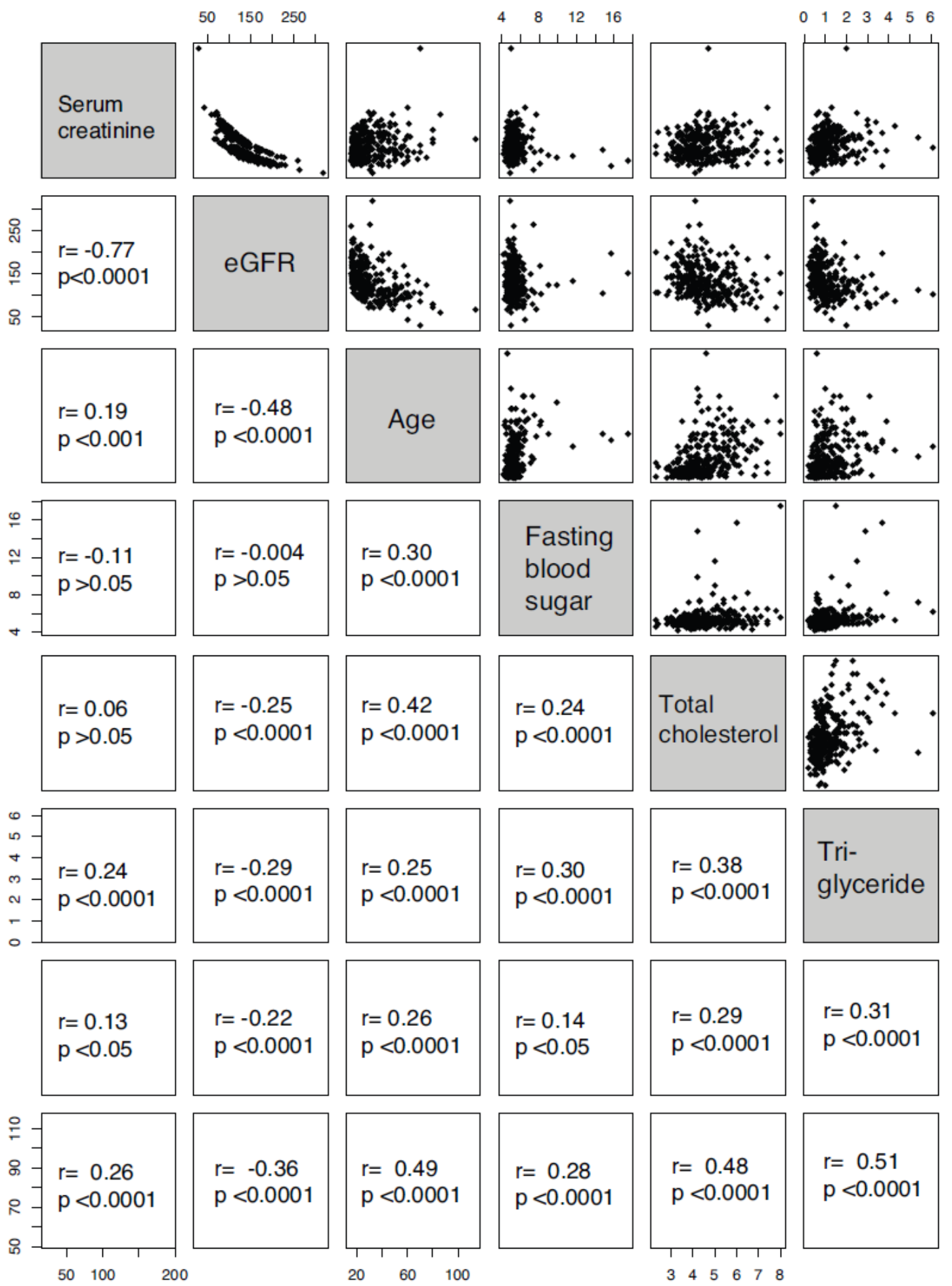
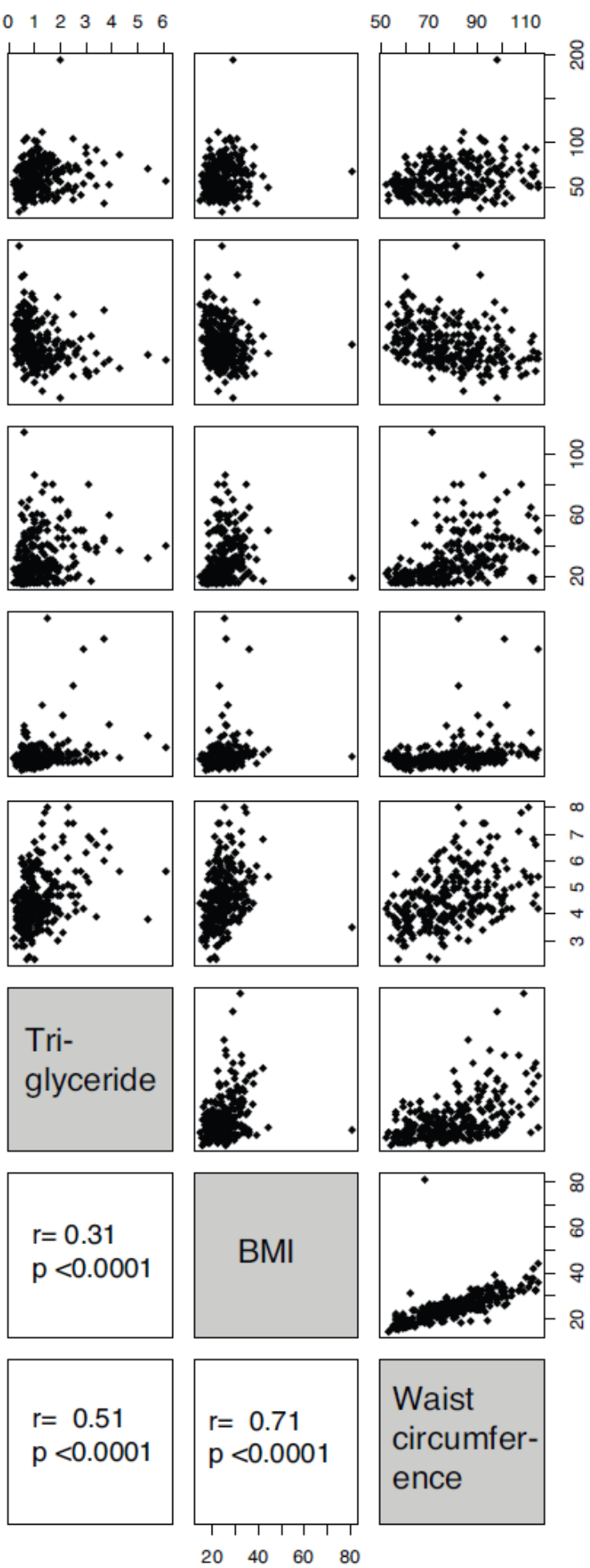

\section{Figure 1}

Scatter plot matrix of serum creatinine and estimated-glomerular Filtration rate (eGFR) and metabolic parameters. Pearson correlation coefficient $(r)$ and $p$-value are shown in the box of the lower panel. BMI: Body Mass Index 
A

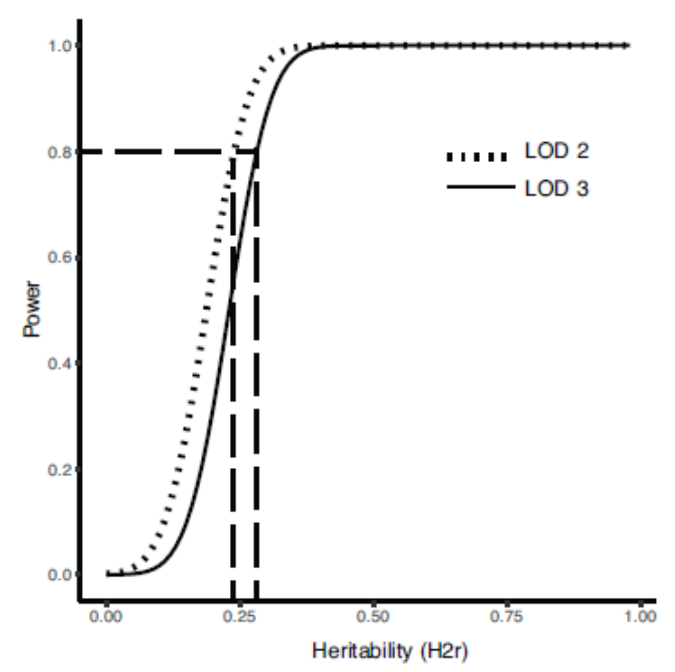

C

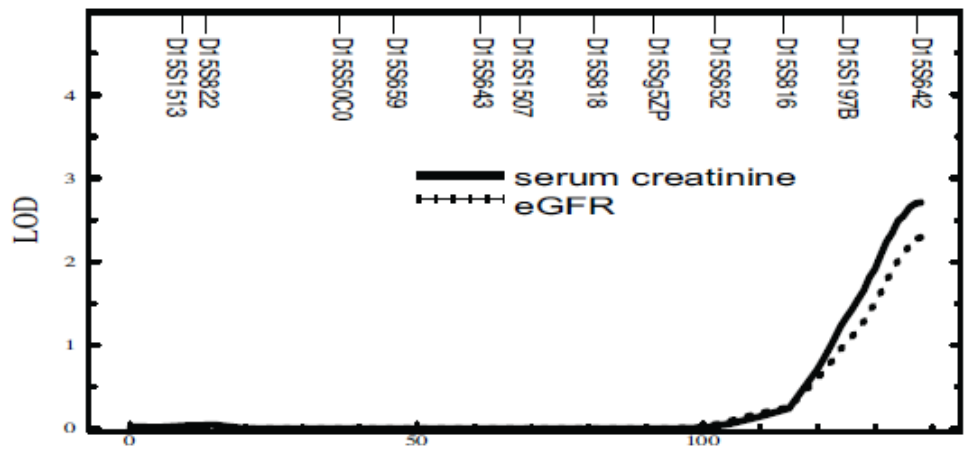

Chromosome Position (cM)
B

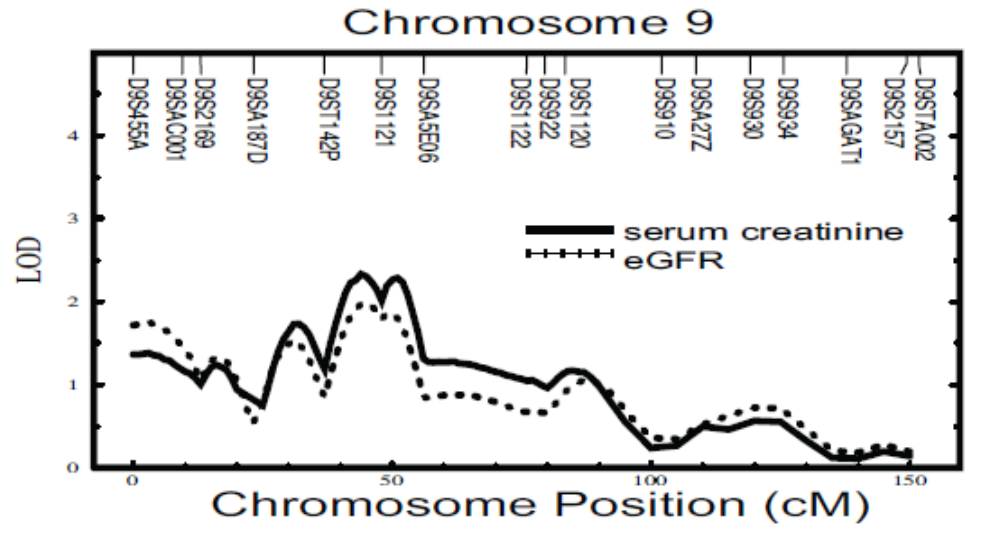

D

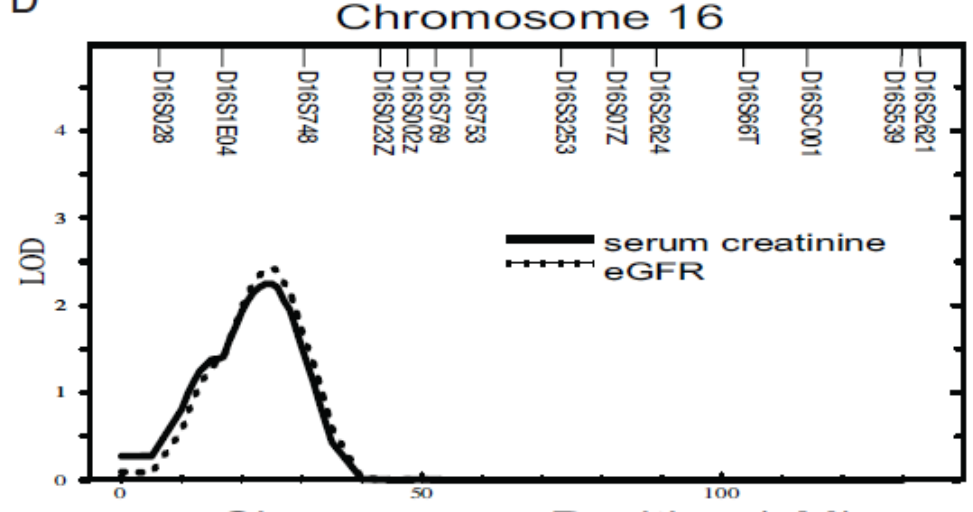

Chromosome Position (cM)

Figure 2

Multipoint quantitative linkage analysis of serum creatinine and eGFR. (A) Pedigree power analysisat significant LOD scores of 2 and 3 for traits of different heritability (0-1). Quantitative linkage analysis with significant LOD score of $\geq 2$ for chromosomes 9 (B), 15 (C) and 16 (D). 